\title{
$\begin{array}{ll}\text { Research Square } & \text { Preprints are preliminary reports that have not undergone peer review. } \\ \text { They should not be considered conclusive, used to inform clinical practice, } & \text { or referenced by the media as validated information. }\end{array}$
}

\section{Comparison of The Effects of Methylphenidate Plus Betahistine and Methylphenidate Plus Placebo on Attention Deficit Hyperactivity Disorder in Children}

\section{Reza Ghanei Gheshlagh}

Kurdistan University of Medical Science: Kurdistan University of Medical Sciences

\section{Sajedeh Nourbehesht}

Kurdistan University of Medical Science: Kurdistan University of Medical Sciences

Pedram Andalibi

Kurdistan University of Medical Science: Kurdistan University of Medical Sciences

\section{Ebrahim Ghaderi}

Kurdistan University of Medical Science: Kurdistan University of Medical Sciences

\section{Fayegh Yousefi}

Kurdistan University of Medical Science: Kurdistan University of Medical Sciences

\section{Soleiman Mohammadzadeh ( $\nabla$ dr.mohammadzadeh1399@gmail.com )}

Kurdistan University of Medical Science: Kurdistan University of Medical Sciences https://orcid.org/0000-0001-8003-9156

\section{Farzin Rezaei}

Kurdistan University of Medical Science: Kurdistan University of Medical Sciences

\section{Research article}

Keywords: Betahistine, Methylphenidate, ADHD, Children

Posted Date: January 14th, 2021

DOI: https://doi.org/10.21203/rs.3.rs-143737/v1

License: (a) (1) This work is licensed under a Creative Commons Attribution 4.0 International License. Read Full License 


\section{Abstract}

Background: Attention deficit hyperactivity disorder (ADHD) is a common disorder during childhood that leads to impairment in functioning in academic and career domains and social responsibility. Methylphenidate is a common treatment for ADHD that may not be taken by patients due to its complications. The goal of the present study is to examine and compare the effects of Methylphenidate plus Betahistine and Methylphenidate plus placebo on ADHD in Children.

Methods: This was a randomized double-blind clinical trial with control group conducted with 76 children with ADHD referred to Be'sat Hospital in Sanandaj, Iran in 2019. The data was collected using the demographic form, a researcher-made form for assessing the reported complications of Methylphenidate and Betahistine, ADHD Rating Scale and the Clinical Global Impression - Severity scale (CGI-S).

Results: There was no age difference between the two experimental groups. Both groups experienced a reduction in intensity of $A D H D$ symptoms according to mean scores, but there was more reduction in the Methylphenidate plus Betahistine than the other group. The most common complications in the two groups were lack of appetite (weeks 2 and 4) and agitation and vertigo (week 2).

Conclusion: Betahistine plus Methylphenidate may be more effective in treating ADHD symptoms compared to Methylphenidate alone.

\section{Background}

Attention deficit hyperactivity disorder (ADHD) is a common disorder during childhood that affects $3-5 \%$ of children (1). This disorder is characterized by inattention, impulsivity, and hyperactivity leading to impairment in functioning in academic and career domains and social responsibility (2). The main cause of ADHD is still unknown, but different studies have found associations between this disorder and genetic factors, prenatal risk factors, pregnancy complications, dysfunctional neurotransmitter systems especially dopaminergic and adrenergic systems, and psychosocial factors (3).

Currently, central nervous system stimulants, such as Methylphenidate and dextroamphetamine are used to treat ADHD that increase dopamine and norepinephrine in parts of the brain (4). Given that ADHD is a neurodevelopmental disorder that can be a lifetime condition, Methylphenidate is often prescribed in the long term (5). Despite the effectiveness of these stimulants in controlling and treating ADHD, about 30\% of children do not respond well to Methylphenidate or cannot tolerate its complications; therefore, it seems necessary to introduce alternative treatments with fewer complications for this condition (6).

Histamine is a biogenic amine with high affinity for the $\mathrm{H}_{3}$ receptor, and has an important role in central

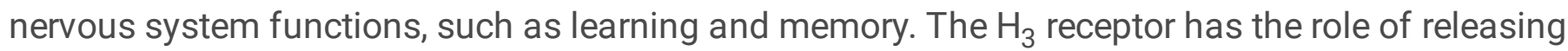
histamine from presynaptic neurons, and is a heterogeneous presynaptic receptor in the peripheral nervous system influencing the release of other neurotransmitters (dopamine and norepinephrine) (7). It has been found that neurotransmitters, such as dopamine, norepinephrine, and acetylcholine play a key 
role in $\mathrm{H}_{3} \mathrm{R}$ improvement (8). Clinical studies have shown that potent and selective $\mathrm{H}_{3}$ antagonists can be used as a novel therapeutic approach for different conditions, such as ADHD, Alzheimer's disease, and schizophrenia (7, 9-11). In addition, clinical models for treating ADHD have shown that increased synthesis of histamine and neurotransmitters through the histamine $\mathrm{H}_{3}$ receptor antagonist can effectively improve attention and reduce impulsivity $(7,12)$.

The stimulants currently used are effective in controlling and treating ADHD, however, a significant percentage of patients either do not respond well to them or cannot tolerate their complications; therefore, introduction of alternative treatments with fewer complications seem to be necessary. Therefore, the present study aims to examine and compare the effects of Methylphenidate plus Betahistine and Methylphenidate plus placebo on ADHD symptoms in Children.

\section{Methods}

This is a randomized double-blind clinical trial with control group conducted in 2019. The statistical population includes all children with ADHD referred to Be'sat Hospital in Sanandaj who were selected using a convenience sampling method. Based on the results of a study by Mohammadi et al. (2015) (13), and considering a type 1 error of 0.05 and mean ADHD scores of $4.8 \pm 13.9$ and $4.4 \pm 10.8$ in the two groups at the end of the study, and using the following formula $\mathrm{N}:=\frac{2 \sigma^{2}\left(z_{\beta}+Z_{\alpha / 2}\right)^{2}}{\text { Difference }^{2}}$, a sample size of $n=36$ was calculated for each study group that was increased to 38 due to possible attrition. ADHD was diagnosed by three child and adolescent psychiatrists based on the DSM- 5 criteria and the Kiddie Schedule for Affective Disorders and Schizophrenia (K-SADS) as a semi-structured diagnostic interview. Aged 6-12 years and diagnosis of ADHD based on the diagnostic criteria of DSM-5 were the inclusion criteria. In addition, the exclusion criteria were as follows: serious physical disorders, such as cardiovascular disease; asthma; peptic ulcer disease; pheochromocytoma and G6PD according to family health history of the patient and clinical examination; comorbid psychiatric disorders, except oppositional defiant disorder; mental retardation according to clinical examination; taking ADHD medications during the past month; history of allergy to Betahistine; and systolic blood pressure above $125 \mathrm{mmhg}$ or a resting pulse of fewer than $60 \mathrm{BPM}$ or more than $115 \mathrm{BPM}$.

\section{Ethical considerations}

Before starting the study, the study objectives and procedure were explained to the patients and their families, and they were reassured that they could leave the study at any time. In addition, they were given a phone number to contact the researcher. Moreover, they were not required to spend any money during the study. Furthermore, written and verbal consent for participation in the study were obtained from parents and children, respectively. The present study was approved by the ethics committee at Kurdistan University of Medical Sciences according to the declaration of Helsinki (No. IR.MUK.REC.1396.263). In addition, it was registered in the Iranian Registry of Clinical Trials (www.irct.ir) (No. IRCT Id: IRCT20160530028182N6). 


\section{Measurement tools}

The data was gathered using the demographic form, a researcher-made form assessing the reported complications of Methylphenidate and BetahistineADHD Rating Scale, and the Clinical Global Impression - Severity scale (CGI-S).

The ADHD Rating Scale is used to measure the severity of ADHD symptoms and respond to treatment in children and adolescents. It has 18 items in two dimensions, including attention deficit and hyperactivity. The items are rated on a 4-point Likert-type scale ranging from 0 to 3 . In order to reduce response bias, items assessing attention deficit have odd numbers and those assessing hyperactivity/impulsivity have even numbers. Total score is the sum of raw scores on the two dimensions. Raw scores are converted to standard scores (percent scores) according to the normative table of the scale that is based on the child's age and gender. The scale has an internal consistency of 0.92 and a one-month test-retest reliability of 0.85 (14).

The CGI-s requires the clinician to assess the severity of the patient's condition. It was used in the presents study to assess the severity of ADHD and patient's response to treatment. It has 7 subscales, including normal, borderline mentally ill, mildly ill, moderately ill, markedly ill, severely ill, extremely ill.

\section{Intervention}

The severity of symptoms before the intervention was assessed using the ADHD Rating Scale and the CGI-s. Before the intervention, the participants have undergone a physical examination in terms of heart rate, blood pressure, and weight. In the next step, the patients were divided into two groups, a Methylphenidate (Ritalin made by Novartis) plus Betahistine (Betaserc by Abbott) group and another Methylphenidate plus placebo group. The patients were randomly divided into the two groups. Then a pharmacist put the required drugs in boxes with closed doors and codes written on them, and gave them to the patients in the order in which they arrived. Neither the physician nor the patients were aware of the content of each box. Methylphenidate and Betahistine pills were crushed and put into similar capsules. Ritalin $10 \mathrm{mg}$ and Betahistine $8 \mathrm{mg}$ tablets were prescribed as follows: during the first week, once a day (Half of tablet at $8 \mathrm{am}$ and another half at $2 \mathrm{pm}$ ), and from the second week, 2 tablets once a day (One tablet at 8 am and another at $2 \mathrm{pm}$ ). The patients were assessed again using the ADHD Rating Scale and the CGI-s in the week zero, and then in the second, fourth, and sixth weeks of the intervention period. In addition, the form assessing drug complications was completed in the second, fourth, and sixth weeks of the intervention period. If a patient could not tolerate the complications of a drug, the dosage of it was reduced and increased in smaller increments; all these details were recorded in patient medical records.

\section{Data analysis}

Descriptive statistics, including relative and absolute frequencies, mean, median, standard deviation, and range were used to describe the data. In addition, at the inferential statistics level, the repeated measures 
ANOVA was used to compare the means of quantitative variables between the intervention and control groups. All the analyses were performed using SPSS v.18. The significance level was set at $p<0.05$.

\section{Results}

The groups receiving Methylphenidate plus Betahistine included 30 boys and 8 girls (with a mean age of $10.26 \pm 2.01$ years) and the group receiving Methylphenidate plus placebo included 26 boys and 12 girls (with a mean age of $10.18 \pm 2.45$ years). The demographic description of the participants is presented in Table 1.

Table 1 Demographic description of the participants in the two groups 


\begin{tabular}{|c|c|c|c|}
\hline Variable & $\begin{array}{l}\text { Methylphenidate plus } \\
\text { Betahistine }\end{array}$ & $\begin{array}{l}\text { Methylphenidate plus } \\
\text { placebo }\end{array}$ & $\begin{array}{l}P- \\
\text { value }\end{array}$ \\
\hline Age & $10.26 \pm 2.01$ & $10.18 \pm 2.44$ & 0.878 \\
\hline Weight & $39.44 \pm 11.76$ & $37.76 \pm 11.03$ & 0.522 \\
\hline \multicolumn{4}{|l|}{ Gender } \\
\hline Girl & $8(21.1 \%)$ & $12(31.6 \%)$ & \multirow[t]{2}{*}{0.435} \\
\hline Boy & $30(78.9 \%)$ & $26(68.4 \%)$ & \\
\hline \multicolumn{4}{|l|}{ Father's job } \\
\hline Unemployed & $4(12.9 \%)$ & $1(2.7 \%)$ & \multirow[t]{2}{*}{0.17} \\
\hline Employed & $27(87.1 \%)$ & $36(97.3 \%)$ & \\
\hline \multicolumn{4}{|l|}{ Mother's job } \\
\hline Unemployed & $35(94.6 \%)$ & $35(94.6 \%)$ & \multirow[t]{2}{*}{1} \\
\hline Employed & $2(5.4 \%)$ & $2(5.4 \%)$ & \\
\hline ADHD Rating Scale & $41.86 \pm 2.01$ & $42.47 \pm 6.93$ & 0.733 \\
\hline \multicolumn{4}{|l|}{$\begin{array}{l}\text { Dose of } \\
\text { Methylphenidate }\end{array}$} \\
\hline Week 1 & $10 \mathrm{mg} /$ day & 10mg/day & \multirow[t]{3}{*}{1} \\
\hline Week 2 & $20 \mathrm{mg} /$ day & 20mg/day & \\
\hline Weeks 4 and 6 & 20mg/day & 20mg/day & \\
\hline \multicolumn{4}{|l|}{ Dose of Betahistine } \\
\hline Week 1 & 8mg/day & - & \multirow[t]{3}{*}{1} \\
\hline Week 2 & $16 \mathrm{mg} / \mathrm{day}$ & - & \\
\hline Weeks 4 and 6 & $16 \mathrm{mg} /$ day & - & \\
\hline
\end{tabular}

\section{Drug complications}

In the Methylphenidate plus Betahistine group, the most common complication in the second and fourth weeks was lack of appetite; and in the Methylphenidate plus placebo group, the most common complications in the second weeks were agitation and vertigo.

\section{Severity of ADHD}

The severity of ADHD in both groups reduced over time, but there was more reduction in the Methylphenidate plus Betahistine group compared the other group (Table 2 and Figure 1). 
Table 2: Mean score of ADHD in different weeks of intervention

\begin{tabular}{|lll|}
\hline M \pm Sd & Time & Group \\
\hline $41.87 \pm 8.39$ & Before starting the treatment & Methylphenidate plus Betahistine \\
\hline $39.45 \pm 8.37$ & Second week & \\
\hline $35.08 \pm 8.02$ & Forth week & \\
\hline $31.63 \pm 8.40$ & Sixth week & \multirow{2}{*}{ Methylphenidate and placebo } \\
\hline $42.47 \pm 6.93$ & Before starting the treatment & \\
\hline $39.13 \pm 6.63$ & Second week & \\
\hline $36.45 \pm 6.71$ & Forth week & \\
\hline $33.79 \pm 6.85$ & Sixth week & \\
\hline
\end{tabular}

Table 3 Mean and standard deviation of ADHD in different weeks of the study 


\begin{tabular}{|c|c|c|c|c|c|c|}
\hline \multirow[t]{2}{*}{$P$} & \multicolumn{2}{|c|}{$\begin{array}{l}\text { Methylphenidate plus } \\
\text { placebo }\end{array}$} & \multicolumn{2}{|c|}{$\begin{array}{l}\text { Methylphenidate plus } \\
\text { Betahistine }\end{array}$} & \multirow{2}{*}{$\begin{array}{l}\text { Group } \\
\text { Time/trend }\end{array}$} & \\
\hline & $\%$ & $\mathrm{n}$ & $\%$ & $\mathrm{n}$ & & \\
\hline \multirow[t]{3}{*}{0.602} & 0 & 0 & 2.6 & 1 & $\begin{array}{l}\text { Maximum } \\
\text { recovery }\end{array}$ & $\begin{array}{l}\text { Before starting the } \\
\text { treatment }\end{array}$ \\
\hline & 13.2 & 5 & 13.2 & 2 & $\begin{array}{l}\text { Minimal } \\
\text { recovery }\end{array}$ & \\
\hline & 86.8 & 33 & 84.2 & 32 & Unchanged & \\
\hline \multirow[t]{3}{*}{0.741} & 2.6 & 1 & 2.6 & 1 & $\begin{array}{l}\text { Maximum } \\
\text { recovery }\end{array}$ & Second week \\
\hline & 73.7 & 28 & 65.8 & 25 & $\begin{array}{l}\text { Minimal } \\
\text { recovery }\end{array}$ & \\
\hline & 23.7 & 9 & 31.6 & 12 & Unchanged & \\
\hline \multirow[t]{3}{*}{0.261} & 23.5 & 8 & 41.7 & 15 & $\begin{array}{l}\text { Maximum } \\
\text { recovery }\end{array}$ & Fourth week \\
\hline & 67.6 & 23 & 50 & 18 & $\begin{array}{l}\text { Minimal } \\
\text { recovery }\end{array}$ & \\
\hline & 8.8 & 3 & 8.3 & 3 & Unchanged & \\
\hline \multirow[t]{3}{*}{0.332} & 47.8 & 11 & 81.2 & 26 & $\begin{array}{l}\text { Maximum } \\
\text { recovery }\end{array}$ & Sixth week \\
\hline & 52.2 & 12 & 15.6 & 5 & $\begin{array}{l}\text { Minimal } \\
\text { recovery }\end{array}$ & \\
\hline & 0 & 0 & 3.1 & 1 & Unchanged & \\
\hline
\end{tabular}

In addition, no significant difference was observed between the two groups in the second week of the study in terms of the effects of Betahistine. However, in the fourth week, more than $40 \%$ of participants in the Methylphenidate plus Betahistine group had maximum recovery, while this was only $23 \%$ in the Methylphenidate plus placebo group. In the same week, minimal recovery was found to be $50 \%$ and $68 \%$ in the Methylphenidate plus Betahistine and Methylphenidate plus placebo groups, respectively. In the sixth week of the study, maximum and minimum recovery rates in the Methylphenidate plus Betahistine group were found to be $80 \%$ and $16 \%$, respectively. In the same week, maximum and minimum recovery rates in the Methylphenidate plus placebo group were found to be $48 \%$ and $52 \%$, respectively. Overall, the results showed no significant difference between the study groups in terms of recovery before the intervention, and in the second, forth, and sixth weeks of the study.

\section{Discussion}


The goal of the present applied, double-blind clinical trial was to compare the effects of Methylphenidate plus Betahistine and Methylphenidate plus placebo on ADHD in Children. According to the results, there was no significant difference between the two groups in the level of recovery from ADHD symptoms. In other words, adding Betahistine to the treatment regimen of ADHD patients did not reduce the severity of their symptoms, but the mean score of ADHD severity indicated that participants in the Methylphenidate plus Betahistine group experienced a greater decrease in their symptoms than those in the Methylphenidate plus placebo group. More specifically, in the fourth week of the study, more than $40 \%$ of participants in the Methylphenidate plus Betahistine group had maximum recovery, while this was $23 \%$ in the Methylphenidate plus placebo group; and in the sixth week of the study, more than $80 \%$ of participants in the Methylphenidate plus Betahistine group had maximum recovery, while this was found to be $48 \%$ in the Methylphenidate plus Betahistine group.

The results of our study are consistent with those found by Weisler et al. (2012). In their study on 430 adults with ADHD, participants were given different doses of Betahistine (1 $1 \mathrm{mg}, 3 \mathrm{mg}$, or $10 \mathrm{mg}$ ) once a day; it was found that none of the doses of the drug had a significant clinical impact on ADHD symptoms, and that the two groups receiving low doses of the drug tolerated it well, but the group receiving $10 \mathrm{mg}$ Betahistine per day had a lower drug tolerance and were more likely to stop taking the drug (9). In their study focused on examining the effects of histamine pharmacokinetics in doses higher than $50-200 \mathrm{mg}$ on symptoms of ADHD, Moorthy et al. (2015) found a linear association between dose of Betahistine and maximum plasma concentration and time to reach peak plasma concentration (15); this findings is also in line with the study results. We did not find a significant relationship, but maximum recovery was more observable in the forth and second weeks of the study.

Clinical models for treating ADHD show that increased synthesis of histamine and neurotransmitters through the $\mathrm{H}_{3}$ receptor antagonist effectively improves concentration and reduces impulsivity $(7,12)$. The $\mathrm{H}_{3}$ receptor has the role of releasing histamine from presynaptic neurons in the CNS, and is a heterogeneous presynaptic receptor in the PNS that increases the release of other neurotransmitters (dopamine and norepinephrine) (7). It has been shown that neurotransmitters, such as dopamine, norepinephrine, and acetylcholine have a key role in $\mathrm{H}_{3} \mathrm{R}$ improvement (8). Clinical studies have shown that the $\mathrm{H}_{3}$ histamine receptor can be used to treat cognitive disorders, such as ADHD, Alzheimer's disease, and schizophrenia $(7,9-11)$. The $H_{3}$ histamine receptor is a potent antagonist $(16,17)$ that is orally prescribed to treat vertigos associated to the vestibular system like those experienced in the Ménière's disease $(10,18,19)$. In our study, few complications were reported. Reduced appetite was the most common complication in the Methylphenidate plus Betahistine group, and vertigo and agitation were the most common complications in the Methylphenidate plus placebo group. Consistent with this finding, Moorthy et al. reported no serious complication of Betahistine (15). It is worthwhile to note that we could not find any similar study to compare their results with our results.

The study results showed that Betahistine plus Methylphenidate may be more effective in treating ADHD compared to Methylphenidate alone, but further studies on this subject are needed to show the long-term 
effects of this method. One of the study limitations was that we could not find many related studies; therefore, a small literature related to the study subject was available. It is suggested that more clinical trials with larger samples should be conducted on this subject, and that the present study should be replicated with children under treatment with other drugs and also with people in other age groups so that the results could be compared with those of the present study.

\section{Conclusion}

According to the results of the present study, and given the few complications of Betahistine, if future studies confirm the effectiveness of this drug in treating ADHD, it can be used in cases where other therapies are not effective.

\section{Abbreviations}

ADHD: Attention deficit hyperactivity disorder

CGI-S: Clinical Global Impression - Severity scale

IRCT: Iranian Registry of Clinical Trials

K-SADS: Kiddie Schedule for Affective Disorders and Schizophrenia

\section{Declarations}

\section{Ethics approval and consent to participate}

All procedures performed in studies involving human participants were in accordance with the ethical standards of the institutional and/or national research committee and with the 1964 Helsinki declaration and its later amendments or comparable ethical standards. Informed Consent Informed consent was obtained from parents of all participants included in the study.

\section{Consent for publication}

Not applicable

\section{Availability of data and material}

The datasets used and/or analyzed during the current study are available from the corresponding author on reasonable request.

\section{Competing interests}

The authors declare that they have no competing interests. 


\section{Funding}

This work was supported by funding from the Kurdistan University of Medical Science (No. 1396.263). The funders played no role in the study design, data collection and analysis, decision to publish, or preparation of the manuscript.

\section{Authors' contributions}

RGH: writing the paper, RGG, SN and SM: designed the research (project conception, development of overall research plan, and study oversight), FY and PA: conducted research (conduct of the assessments and data collection), EG and FR: statistical analysis. All authors contributed significantly to the intellectual design, provided critical revisions to the manuscript and approved the final version. All authors read and approved the final manuscript.

\section{Acknowledgements}

This study was part of an approved research proposal in Kurdistan University of Medical Sciences. In this regard, the researchers thanked the Research Deputy of Kurdistan University of Medical Sciences for approving this proposal.

\section{References}

1. Sayal K, Prasad V, Daley D, Ford T, Coghill D. ADHD in children and young people: prevalence, care pathways, and service provision. The Lancet Psychiatry. 2018;5(2):175-86.

2. Addicott MA, Schechter JC, Sapyta JJ, Selig JP, Kollins SH, Weiss MD. Methylphenidate increases willingness to perform effort in adults with ADHD. Pharmacology Biochemistry and Behavior. 2019;183:14-21.

3. Sadock BJ. Behavioral Sciences/Clinical Psychiatry Eleventh Edition. Wolters Kluwer; 2007.

4. Wilens TE. Mechanism of action of agents used in attention-deficit/hyperactivity disorder. The Journal of clinical psychiatry. 2006;67:32-8.

5. Krinzinger H, Hall CL, Groom MJ, Ansari MT, Banaschewski T, Buitelaar JK, et al. Neurological and psychiatric adverse effects of long-term Methylphenidate treatment in ADHD: A map of the current evidence. Neuroscience \& Biobehavioral Reviews. 2019;107:945-68.

6. Glanzman MM. ADHD and nutritional supplements. Current Attention Disorders Reports. 2009;1(2):75-81.

7. Esbenshade T, Browman K, Bitner R, Strakhova M, Cowart M, Brioni J. The histamine H3 receptor: an attractive target for the treatment of cognitive disorders. British journal of pharmacology. 2008;154(6):1166-81.

8. Arrang J-M, Garbarg M, Schwartz J-C. Auto-inhibition of brain histamine release mediated by a novel class (H 3) of histamine receptor. Nature. 1983;302(5911):832-7. 
9. Weisler RH, Pandina GJ, Daly EJ, Cooper K, Gassmann-Mayer C. Randomized clinical study of a histamine $\mathrm{H} 3$ receptor antagonist for the treatment of adults with attention-deficit hyperactivity disorder. CNS drugs. 2012;26(5):421-34.

10. Lacour M, Sterkers 0 . Histamine and Betahistine in the treatment of vertigo. CNS drugs. 2001;15(11):853-70.

11. Hancock AA, Esbenshade TA, Krueger KM, Yao BB. Genetic and pharmacological aspects of histamine H3 receptor heterogeneity. Life sciences. 2003;73(24):3043-72.

12. Arrang J-M, Morisset S, Gbahou F. Constitutive activity of the histamine $\mathrm{H} 3$ receptor. Trends in pharmacological sciences. 2007;28(7):350-7.

13. Mohammadi MR, Mohammadzadeh S, Akhondzadeh S. Memantine versus Methylphenidate in children and adolescents with attention deficit hyperactivity disorder: a double-blind, randomized clinical trial. Iranian journal of psychiatry. 2015;10(2):106.

14. Zhang S, Faries D, Vowles M, Michelson D. ADHD rating scale IV: psychometric properties from a multinational study as clinician-administered instrument. International journal of methods in psychiatric research. 2005;14(4):186-201.

15. Moorthy G, Sallee F, Gabbita P, Zemlan F, Sallans L, Desai PB. Safety, tolerability and pharmacokinetics of 2-pyridylacetic acid, a major metabolite of Betahistine, in a phase 1 dose escalation study in subjects with ADHD. Biopharmaceutics \& drug disposition. 2015;36(7):429-39.

16. Gbahou F, Davenas E, Morisset S, Arrang J-M. Effects of Betahistine at histamine H3 receptors: mixed inverse agonism/agonism in vitro and partial inverse agonism in vivo. Journal of Pharmacology and Experimental Therapeutics. 2010;334(3):945-54.

17. Arrang J-M, Garbarg M, Quach TT, Tuong MDT, Yeramian E, Schwartz J-C. Actions of Betahistine at histamine receptors in the brain. European journal of pharmacology. 1985;111(1):73-84.

18. Lacour $M$, van de Heyning PH, Novotny $M$, Tighilet B. Betahistine in the treatment of Ménière's disease. Neuropsychiatric disease and treatment. 2007;3(4):429.

19. Hommes O. A study of the efficacy of Betahistine in Meniere's syndrome. Acta Oto-Laryngologica. 1972;74(sup305):70-9.

\section{Figures}




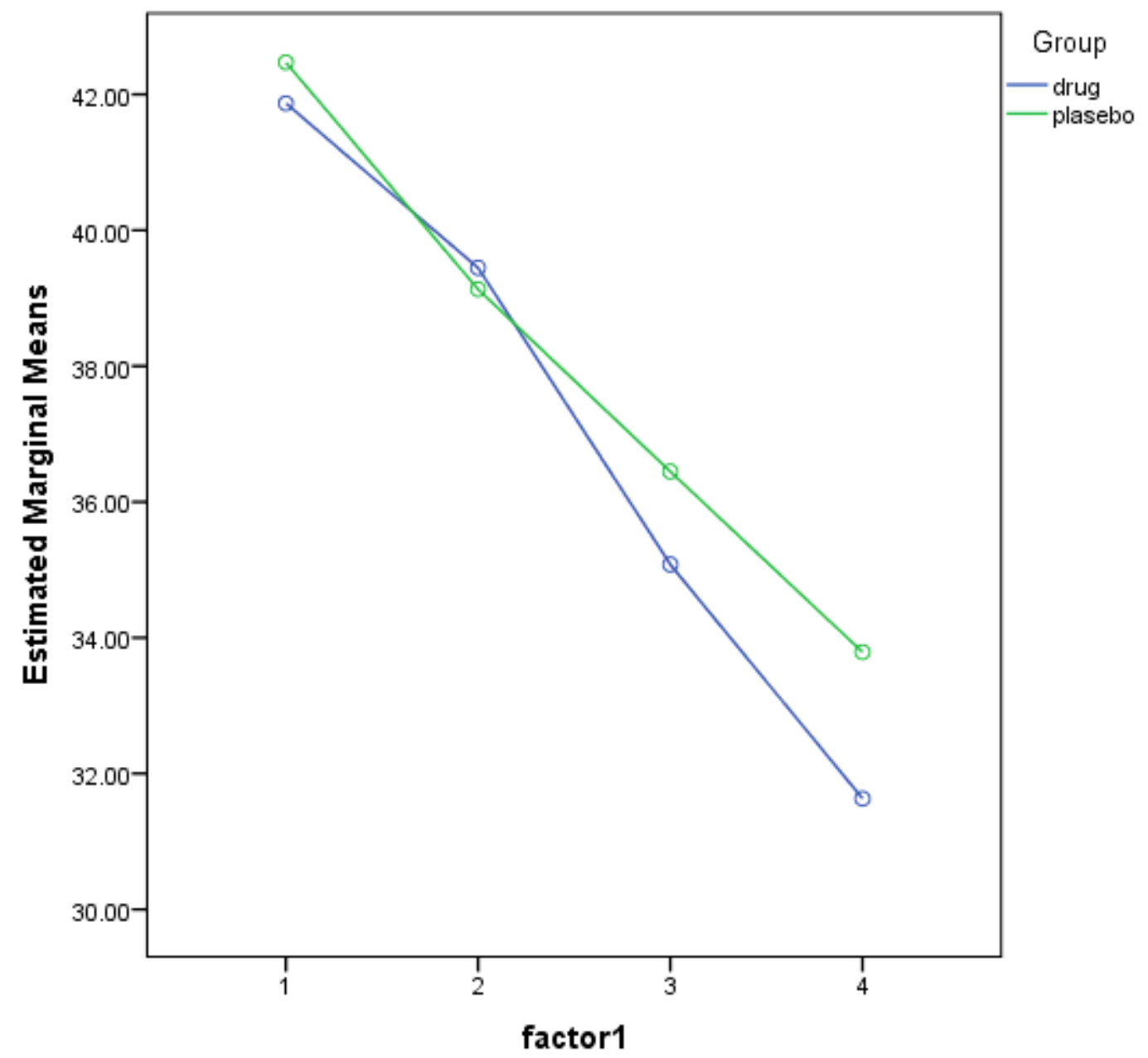

Figure 1

Severity of ADHD in children in the two intervention groups in different weeks of the study. 